\title{
Palavrões e xingamentos para a compreensão da italianidade ${ }^{1}$
}

\author{
Palabrotas y insultos para la comprensión de la italianidad \\ Swear words and curse expressions for the understanding of italianity
}

Wânia Cristiane Beloni²

\begin{abstract}
Resumo
Quando se aprende uma língua estrangeira aprende-se, também, novas concepções de mundo. Quando se trabalha aspectos culturais em sala de aula, possibilita-se o desenvolvimento da competência comunicativa e, consequentemente, do conhecimento sociocomunicativo e intercultural. Compreender fatores históricos, geográficos e sociais, os quais, consequentemente, delineiam as variedades linguísticas e culturais de uma comunidade, assim como algumas marcas de identificação étnica, possibilita ao estudante de língua estrangeira a ampliação de conhecimentos fundamentais para a compreensão da cultura do outro, assim como da própria. Os palavrões e xingamentos são itens lexicais utilizados pelos italianos, assim como pelos italodescendentes. Nesse sentido, para compreender a importância desse campo lexical para a cultura italiana, propõe-se uma análise de alguns termos, coletados em pesquisa de campo, citados e relembrados por 18 entrevistados, descendentes de italianos de colonização sulista que moram em Cascavel/PR, assim como da análise dos livros didáticos de italiano como língua estrangeira Domani e Magari, ambos da Alma Edizioni. Para isso, a Linguística Aplicada será relacionada à Sociolinguística, a estudos culturais, identitários e históricos.
\end{abstract}

Palavras-chave: Ensino intercultural; Italodescendentes; Material didático.

\section{Resumen}

Cuando se aprende una lengua extranjera, se aprenden, también, nuevas concepciones de mundo. Cuando se trabajan, aspectos culturales en el aula, se posibilita el desarrollo de la competencia comunicativa $y$, consecuentemente, del conocimiento sociocomunicativo e intercultural. Comprender factores históricos, geográficos y sociales, que, en consecuencia, señalan las variedades lingüísticas y culturales de una comunidad, así como algunas marcas de identificación étnica, posibilita al estudiante de lengua extranjera la ampliación de los conocimientos fundamentales para la comprensíon de la cultura del outro, así como de la propia. Las palabrotas y los insultos son elementos lexicales utilizados por los italianos y por los ítalo-descendientes. En este sentido, para compreender la importancia de este campo lexical para la cultura italiana, se propone un análisis de algunos términos, recogidos en investigación de campo, citados y recordados por 18 entrevistados, descendientes de italianos de la colonización sureña que viven en Cascavel/PR, así como del análisis de los libros didácticos de italiano como lengua extranjera Domani y Magari, ambos de Alma Edizioni. Para ello, la Lingüística Aplicada será relacionada a la Sociolingüística, a estudios culturales, identitarios e históricos.

Palabras-clave: Enseñanza intercultural, material didáctico, ítalo-descendientes.

\begin{abstract}
Once one learns a foreign language, one also learns new conceptions of the world. When working with cultural aspects in the classroom, it is possible to develop communicative competence and, consequently,

\footnotetext{
${ }^{1}$ Artigo apresentado no Simpósio Temático (A perspectiva intercultural em estudos sobre língua(s) de imigrantes e de fronteiras) durante o II Seminário Latino-Americano de Estudos em Cultura - SEMLACult em Foz do Iguaçu/PR, Brasil, 2018.

${ }^{2}$ Mestre em Letras; Universidade Estadual do Oeste do Paraná (Unioeste); Cascavel, Paraná, Brasil; bolsista Capes; wania.beloni@hotmail.com
} 
sociocommunicative and intercultural knowledge. Understanding historical, geographic and social factors, which as a result delineate the linguistic and cultural range of a community, as well as some ethnic identification marks, enables the foreign language students to expand essential knowledge for understanding the culture of the other, as well as their own. Swear words and curse expressions are lexical items used by Italians and Italian descendants. In this sense, to understand the importance of this lexical field for Italian culture, we proposed an analysis of some terms, collected in field research, quoted and recalled by 18 interviewees, Italian descendants from Southern colonization who live in Cascavel city. Terms in two textbooks of Italian as a foreign language Domani and Magari, both from Alma Edizioni, were also analyzed. For this, Applied Linguistics has been related to Sociolinguistics, to cultural, identity and historical studies.

Keywords: Intercultural education, learning material, Italian descendants.

\section{Introdução}

Compreender a realidade cultural que nos cerca é um desafio para qualquer indivíduo, e que precisa, a partir de suas experiências, romper com preconceitos e estigmas quanto à cultura e à forma de falar do outro. Nesse sentido, as perspectivas sociolinguísticas e interacionais podem auxiliar no ensino-aprendizagem de uma língua.

Escolher um material didático de italiano como língua estrangeira (LE) é um desafio para o professor que se encontra em um contexto de colonização italiana. Ensinar a língua padrão, sem desconsiderar o cenário cultural e linguístico em que os alunos se encontram, trabalhando aspectos culturais em sala de aula é uma maneira de formar não apenas falantes competentes linguisticamente, mas é um dever social contribuir com o desenvolvimento e o conhecimento intercultural dos estudantes.

Rojo (2013) observa que o professor competente ou eficiente é aquele que vai além das limitações do livro didático, o qual tem caráter complexo e por isso não pode contemplar todas as especificidades de um determinado contexto. Sendo assim, deve-se complementar, ajustar e/ou aprofundar determinado conteúdo ou tema abordado no material didático, assim como apresentar e relacionar assuntos que o manual não contemple, mas que sejam necessários para o desenvolvimento do conhecimento e da formação intercultural do estudante, de uma forma crítica e reflexiva.

Os palavrões e xingamentos são vocábulos utilizados pelos italianos, assim como pelos italodescendentes. Nesse sentido, para compreender a importância desse campo lexical para a cultura italiana, propõe-se uma análise de alguns termos, coletados em pesquisa de campo, citados e relembrados por 18 entrevistados, descendentes de italianos de colonização sulista que moram em Cascavel/PR, assim como da análise dos livros didáticos de italiano como língua estrangeira Domani e Magari, ambos da Alma Edizioni, os quais são utilizados para o ensino formal, em Cascavel/PR. Para tanto, faz-se uma reflexão sobre a Linguística 
Aplicada relacionada à Sociolinguística, tratando de estudos culturais e históricos quando se investiga uma comunidade de imigrantes e seus descendentes, assim como o ensino de língua estrangeira nesse contexto.

\section{Italodescendentes em Cascavel/PR entre marcas de identificação étnica e estereótipos}

Em Cascavel, no Oeste do Paraná, há muitos descendentes de italianos e por isso, o professor de língua italiana (LI) padrão precisa considerar a história de muitos alunos e lembrar que os antepassados de muitos desses estudantes vieram da Itália e trouxeram com eles a língua italiana dialetal e a cultura da região de origem europeia, assim como a brasileira, uma vez que muitos descendentes de italianos vieram de outros estados para o Paraná.

Os italodescendentes conservam ou trazem na memória, ainda hoje, muitos termos do dialeto italiano, entre eles, palavrões e xingamentos. Compreender essa questão linguística é essencial para que se entenda aspectos culturais não apenas do descendente italiano, mas também do italiano contemporâneo. Contemplar, portanto, esse aspecto cultural é uma forma de compreender não apenas aspectos linguísticos, mas, também, culturais, que envolvem os alunos de língua italiana como língua estrangeira em contexto de colonização.

Deve-se lembrar, antes de tudo, porém, que a maioria dos italianos, ao chegarem ao Brasil, era monolíngue, falava o dialeto de sua região italiana de origem - Veneto, Lombardia, Trentino Alto Ádige e Friuli Venezia Giulia - do Norte da Itália. Como quase $60 \%$ dos imigrantes italianos eram do Vêneto, foi o dialeto desta região que prevaleceu entre eles. "[...] a coiné resultante do contato entre os diferentes dialetos italianos e denominada de dialeto vêneto, vêneto riograndense ou talian foi uma língua franca, pois possibilitou a interação de imigrantes italianos advindos de diferentes regiões" (PERTILE, 2009, p. 32). Nesse contexto, surge, então, uma nova variação linguística que teve no início função de koiné, ou seja, de comunicação entre famílias italianas que tinham modos de falar distintos. Com base no dialeto vêneto, as famílias italianas, em um novo contexto, em que se falava português, quando se tornaram bilíngues, acabaram transformando o dialeto vêneto. Este sofreu influências do português e assim se transformou em um novo modo de falar, chamado de talian, ou de vêneto brasileiro, o qual está presente, também, no oeste do Paraná.

Junto com a língua, os italodescendentes trouxeram para Cascavel a própria cultura, crenças, concepções e formas de agir no mundo, (des/re)construindo a própria identidade e italianidade em um novo contexto. Entende-se que, portanto, as identidades são construídas 
por meio da linguagem. Em situações históricas e institucionais determinadas, a enunciação é específica e estratégica.

A identidade de um indivíduo se constrói na língua e através dela. Isso significa que o indivíduo não tem uma identidade fixa anterior e fora da língua. Além disso, a construção da identidade de um indivíduo na língua e através dela depende do fato de a própria língua em si ser uma atividade em evolução e vice-versa (RAJAGOPALAN, 1998, p. 41).

$\mathrm{O}$ autor esclarece, portanto, que a identidade se constitui na língua e vice-versa. Cultura, língua e identidade estão, assim, em constante relação e (des/re)construção.

Pensarmos na identidade em relação com a língua(gem), considerando a dimensão interdiscursiva da alteridade, é necessário para que se compreenda as concepções, convicções e atitudes dos falantes em relação a uma forma linguística, seja a sua, materna, seja outra, estrangeira e dominante. Esses aspectos estão relacionados, por sua vez, com a cultura da comunidade, sendo que a língua é uma das formas de expressão cultural de um povo, assim como de identificação étnica.

O termo "etnia" já foi compreendido e vinculado à questão biológica, por meio do viés primordialista de pesquisadores da identidade étnica. Desvinculando a designação da questão biológica, encontramos, porém, os fatores situacionistas e de sentimento grupal, os quais estão mais próximos, também, dos estudos sobre identidade.

O antropólogo social da Noruega, Frederik Barth, um dos que defendem a perspectiva situacionista, define grupo étnico como formas de organização social: "Na medida em que os atores usam identidades étnicas para categorizar a si mesmos e outros, com objetivos de interação, eles formam grupos étnicos neste sentido organizacional” (BARTH, 2011, p. 194). Um grupo, no entanto, tem suas regras e rituais. Bottomore (1996, p. 345) deixa claro que um grupo social é um agregado de seres humanos que se relacionam e se compreendem e que cada um, dentro do grupo, "tem consciência do próprio grupo e de seus símbolos".

Desta forma, Barth também observa que para fazer parte de um grupo étnico é preciso enquadrar-se em uma série de restrições, desde o papel que a pessoa pode desempenhar, até sobre os parceiros com que ela pode se relacionar. "Melhor dizendo, considerada estatuto, a identidade étnica domina a maioria dos outros estatutos e define as constelações de estatutos ou personalidades sociais que um indivíduo com aquela identidade pode assumir" (BARTH, 2011, p. 198).

Muitas vezes, as atitudes e os comportamentos de um grupo fazem com que um grupo se diferencie do restante da comunidade, pois para que exista uma identidade étnica é preciso ter uma diferença, algo que diferencie determinado grupo do restante. Machioski define que 
"a identidade étnica aparece no contraste das relações interétnicas, ou seja, trata-se da afirmação de um 'nós' diante dos 'outros"” (MACHIOSKI, 2004, p. 28).

Quando um grupo está inserido em um contexto, em contato com várias culturas, é que as consciências étnicas e linguísticas afloram. Para que um grupo seja étnico, ele precisa ser diferente do contexto em que está inserido, ou seja, só existe etnicidade quando há heterogeneidade, assim como só existe o conceito de variação se há um de padrão. Para os autores, a etnicidade está longe do processo de assimilação: "longe de levar à assimilação, ela tem como efeito aumentar a consciência e a significação da etnicidade" (POUTIGNAT; STREIFF-FENART, 2011, p. 72).

As fronteiras (critério de pertencimento e exclusão) de um grupo étnico são colocadas por meio das diferenças, as quais mantêm esse grupo vivo. São esses confins que o diferenciam da sociedade geral, do contexto ao redor. "O conceito de fronteira de grupo indica um sentido relacional, ou seja, como um grupo se define e como define o outro e, ainda, como é traçada a fronteira entre eles" (BARICHELLO; SANTOS, 2012, p. 191). Nesse sentido, as fronteiras podem ser estabelecidas por língua, cultural, traje, religião, comportamento, etc.

Muitas vezes, no entanto, as fronteiras étnicas acabam sendo interpretadas de forma estereotipada tanto por meio dos membros do grupo como por aqueles fora dele. Os estereótipos acabam, então, simplificando exageradamente os grupos sociais. Eles são incontroláveis e inflexíveis, disseminando representações implícitas, as quais, enraizadas e resistentes a pressões exteriores, acabam sendo vistas como imutáveis. Meira (2010/2011) explica que o estereótipo está a nível da representação mental e que o preconceito se refere à atitude que um indivíduo toma em relação a um grupo e os seus membros. Assim, "a definição de estereótipo é a associação, ou crença, que se tem sobre as características e atributos de um grupo, bem como dos seus membros, que molda a forma como as pessoas pensam e respondem a esse grupo" (MEIRA, 2010/2011, p. 4). Tais aspectos criam relações hierárquicas diferentes entre os indivíduos e os grupos em contato.

Brito e Bona (2014) salientam, ainda, a verossimilhança gerada na formação de estereótipos, os quais acabam tomando força por meio da generalização:

a diferenciação em si acaba sendo posta em xeque, pois, a partir de estereótipos, a diferenciação nós-eles só pode ocorrer no âmbito da irrealidade, do verossímil talvez, mas não comprovada se não por uma generalização que, por ser tão simplista, dificulta relações claras de alteridade. Em outras palavras, dois grupos acabam por não se enxergarem mutuamente com clareza, mas sim a partir de noções disformes acerca do outro (BRITO; BONA, 2014, p. 20). 
Assim, com base na psicologia social, compreendemos que até mesmo a noção que se tem sobre si passa pela irrealidade, a qual é ponderada e impulsionada pela estereotipagem do outro.

Avaliar, portanto, a procedência do estereótipo, por quem é formulado, de qual nacionalidade e grupos sociais determinado sujeito se insere, por exemplo, são fatores necessários para que se compreenda a formulação e a propagação de tais crenças. A formulação de estereótipos se dá a partir de um contexto, o qual deve também ser observado e analisado para que se possa entender os aspectos que o fundamentam. Assim, a maleabilidade dos estereótipos ocorre devido às variações do contexto e da relativização necessária para que não sejam feitas afirmações apressadas e com base em generalizações.

\section{Metodologia}

Realizamos, neste trabalho, uma breve análise das respostas de 18 entrevistados, descendentes de italianos de colonização sulista ou que moram em Cascavel/PR há pelo menos 30 anos, no caso dos mais jovens. As entrevistas foram coletadas por meio do projeto de pesquisa "Estudo sobre línguas em contato no Oeste do Paraná: a língua italiana, o talian e o português", aprovado pelo Comitê de Ética da Unioeste, por meio da Plataforma Brasil, com o número de parecer 289.274, no início de junho de $2013 .^{3}$

Além disso, analisamos os livros didáticos de língua italiana para estrangeiros Domani (níveis A1, A2 e B1) e Magari (B1, B2 e C1), ambos da Alma Edizioni. A seleção dos materiais se deve ao fato de as duas publicações fazerem parte da documentação escolar do curso de Letras Português/Italiano da Universidade Estadual do Oeste do Paraná (Unioeste), Campus de Cascavel.

A análise tem como intuito avaliar principalmente dois aspectos: (1) os palavrões e xingamentos apresentados pelos entrevistados e a relevância dessa questão cultural nos depoimentos; (2) se o material propõe uma abordagem intercultural, considera e/ou apresenta esses termos, possibilitando o desenvolvimento da competência sociolinguística.

\footnotetext{
${ }^{3}$ Os informantes, descendentes de italiano pelo lado paterno prioritariamente, foram colocados nas variáveis: faixa etária e sexo. Com isso, foram estabelecidas as seguintes dimensões: diassexual (masculino e feminino) e diageracional (GI, 20 a 40 anos; GII, 40 a 60 anos; GIII, mais de 60 anos), uma vez que na dissertação Beloni (2015) avaliou as variáveis. Neste trabalho, porém, apesar de os entrevistados serem designados com as mesmas denominações (para preservar a identidade deles), não tem-se o intuito de considerar as variáveis sexual e geracional.
} 
A realização do estudo orienta-se na perspectiva teórica da Sociolinguística Interacional de Gumperz (1998) e da Linguística Aplicada indisciplinar, pelo ensino transversal de línguas, pela vertente INdisciplinar de Moita Lopes (2006) e transgressiva de Pennycook (2006), o qual, envolve pesquisas nas ciências sociais e humanas.

Os fatores históricos, portanto, estão vinculados ao contexto em que os falantes estão e/ou estiveram inseridos. Pensando nesse sentido, acreditamos que o estudo sociolinguístico seja diacrônico por natureza. Hora (2004, p. 18) lembra que uma "teoria da mudança deve, pois, conceber a língua - de um ponto de vista diacrônico e/ou sincrônico - como um objeto possuidor de heterogeneidade sistemática".

Compreende-se, no entanto, a importância de se relacionar a pesquisa de campo, descritiva, à pesquisa escolar, para que se tenha uma proposta de ensino mais coerente com o contexto. Pessanha, Daniel e Menegazzo (2004, p. 63) explicam que para observar a cultura escolar como objeto histórico deve-se considerar e analisar os saberes e valores impostos no espaço escolar. Para isso, os autores notam que é necessário analisar o conjunto de normas e práticas escolares, os comportamentos, e que muitas vezes isso pode ser observado em “cadernos, planos de ensino, livros, provas e material didático geral”. Para os autores, as fontes primárias são "o elemento mais importante para esclarecer lacunas de documentos, de memória, ou mesmo para alterar estereótipos cristalizados e reproduzidos ad aeternum através da utilização apenas de fontes secundárias", ou seja, nem sempre o que está nos documentos oficiais (nacionais, estaduais e até mesmo nos planos de ensino) é o que acontece de fato em sala de aula.

Para Gil (2002, p. 47), as pesquisas elaboradas com base em documentos "são importantes não porque respondem definitivamente a um problema, mas porque proporcionam melhor visão desse problema ou, então, hipóteses que conduzem a sua verificação por outros meios".

Nesse sentido, para Gil (2002), as vantagens da pesquisa documental são: fonte rica e estável de dados; a subsistência ao longo do tempo; a natureza histórica; o baixo custo; a não necessidade de contato com os sujeitos da pesquisa. No entanto, a principal limitação seria a não-representatividade e a subjetividade dos documentos. Assim, partir para uma pesquisa in loco torna-se fundamental para diagnosticar outras questões a serem consideradas, como o contexto histórico de Cascavel e de seus habitantes e por isso, a necessidade de relacionar a pesquisa documental, a análise dos livros didáticos, àquela de campo. Nesse sentido, esta pesquisa se inscreve na perspectiva teórica da Linguística Aplicada, articulada aos estudos variacionistas. 


\section{Análise da presença de termos vulgares na comunidade italodescendente e em livros didáticos de LI}

As atitudes e as concepções de um povo fazem sentido quando estão inseridas em uma realidade cultural, gerada por percursos, contatos e conflitos diversificados. Para compreender isso, conforme Santos (2006), é necessário que se relacionem as ações culturais com os contextos em que são produzidos. Nesse sentido, a organização familiar, alimentar, geográfica, assim como linguísticas, por exemplo, não se organizam de uma determinada maneira ao acaso. Todos as formas de existir e se manifestar no mundo são resultados de processos históricos.

Compreender que as regras de funcionamento de uma outra cultura são e podem ser diferentes é essencial para que se desenvolva um entendimento ampliado e intercultural. Goffman (1998) explica que as "Regras culturais estabelecem como os indivíduos devem se conduzir em virtude de estarem em um agrupamento e estas regras de convivência, quando seguidas, organizam socialmente o comportamento daqueles presentes à situação" (GOFFMAN, 1998, p. 14). Nesse sentido, Gumperz (1998) fala sobre as convenções de contextualização, ou seja, sobre as pistas de natureza sociolinguística que utilizamos para sinalizar as nossas intenções comunicativas.

Quando se analisa termos vulgares, compreende-se que questões linguísticas, paralinguísticas, prosódicas, culturais, históricas, sociais e comportamentais estão relacionadas e são inseparáveis.

Os entrevistados, ao citarem diversos xingamentos, palavrões e blasfêmias, evidenciam o quanto esses termos são representativos na comunidade italodescendente, os quais delineiam e configuram aspectos linguísticos e culturais do grupo:

Tabela 1 - Termos citados pelos entrevistados

Porca miseria (3x), portati tua, porco can(e) (8x), caspita, porco dio (11x), porca madona $(8 x)$, fiol di un can, figlio di un cane, porco zune ( $2 x)$, santa madonna, dio mamma, madona vergina, sacrato, dio cane, sacramento (4x), ti spaco la recia, maledetta sorte, cramegna, bruto rospo, sant'antoni, porca putana, bruta bestia, porco sacrato, porco fumo, cramenti, porco, caspita, mamma mia, fiolo di un cane, Dio cane, sacramegna, caspita, porca pipa, santo antoni, troia, putana, porca vaca di una putana, fiol di un can.

Fonte: Sistematização da pesquisadora 
Entre os palavrões, xingamentos e blasfêmias, podemos identificar, também, algumas expressões de surpresa, tais como: caspita, santa madonna, dio mamma, madona vergina, mamma mia, entre outras, as quais também evidenciam aspectos da cultura italiana.

Há, porém, ainda, os termos reconhecidos pelos entrevistados, por meio do "Método da Sugestão”. Defendida por Thun (2005), essa técnica permite retomar determinadas informações e assim possibilita descrever o léxico passivo e ativo e o registro dos comentários como índices de atitudes e do comportamento linguístico dos falantes. A "sugerência", de Thun, no âmbito da geolinguística, possibilita, ainda, uma macroanálise das atitudes e posições metalinguísticas dos falantes que se encontram em contextos de contato linguístico. Assim, a partir da sugerência os entrevistados reconheceram os seguintes palavrões:

Tabela 2 - Termos reconhecidos pelos entrevistados

$\begin{gathered}\text { Porco Dio }(8 x), \text { porco can }(e)(9 x), \text { santa madona }(9 x), \text { porca madona }(11 x), \text { cazzo }(8 x), \text { porca } \\ \text { troia }(7 x), \text { brutta bestia }(11 x), \text { sacramento }(4 x) \text {, porca miseria }(2 x) \text {, dio santo antoni }(8 x), \\ \text { porca vaca, stronzo, maledetto, porca di una putana. }\end{gathered}$
Fonte: Sistematização da pesquisadora

Quando se sugere outro termo para determinar o mesmo objeto, como Thun recomenda, existe a possibilidade, ainda, de que os entrevistados façam comentários metalinguísticos. Dessa forma, os itens lexicais podem ser atravessados pelas questões metalinguísticas, as quais podem complementar os dados e proporcionar uma análise mais densa sobre a difusão das variedades linguísticas em Cascavel.

A partir da diversidade de termos chulos apresentados, citados e reconhecidos, percebe-se o quanto, de fato, essas expressões fazem parte da cultura do italodescendente. Tal aspecto também está muito presente na cultura do italiano contemporâneo, basta observar a mídia italiana ou, ainda, os livros didáticos Domani e Magari.

No manual Domani 1, na unidade 5 (Che ore sono?, ou seja, Que horas são?), atividade 1, há, por exemplo, um diálogo entre três turistas italianos de diferentes regiões. $\mathrm{O}$ episódio inicia com um turista que, à meia-noite e meia, bate à porta do convento em que está hospedado, o qual fecha à meia-noite. Depois de chamar várias vezes, um vizinho diz que "basta" e joga um balde d'água no rapaz que depois disso o xinga de "scemo" e "cretino".

É interessante notar que o texto auditivo é inserido logo nas primeiras unidades do manual. O segundo exemplo que podemos observar é do livro Magari, em que a unidade 15 é intitulada Non solo parolacce, ou seja, Não apenas palavrões, o que já demonstra a importância do trabalho com essas expressões para alunos de língua italiana como LE. Especificamente na atividade 1c há um diálogo entre um casal italiano que vai a Roma. A 
mulher inicia o diálogo pedindo para o marido para irem ao restaurante La parolaccia, mas ele diz não querer ir pelo fato de os romanos serem vulgares. Mesmo assim eles vão ao local e quando o homem pede uma mesa disponível o garçom diz para ele encontrar sozinho e aquele o chama de "pirla", uma expressão vulgar tipicamente milanesa, utilizada em diversos dialetos da Lombardia, principalmente em Milão. Originalmente, o termo significa pião, mas depois passou a significar o órgão sexual masculino. A partir desse xingamento o garçom utiliza diversos outros, tais como: stronzo, zozza, cazzo.

O diálogo pode ser considerado engraçado pelo fato de o restaurante realmente existir - http://www.cenciolaparolaccia.it/ - e esse aspecto cultural italiano, sendo, também, um estereótipo, ser explorado para atrair turistas.

Ainda nesta unidade 15 do livro Magari, De Giuli, Guastalla e Naddeo (2008, p.175176) apresentam textos que abordam o nível de tolerância com alguns xingamentos, intitulados: “Dare del 'rompic.' si può" e “Dire 'str...' è offensivo". Eles expõem, ainda, nas páginas 182 e 183 o texto "Piccolo viaggio intorno alla parolaccia", de autoria de Roberto Tartaglione, no qual o autor aborda que os palavrões entraram na linguagem comum tanto de homens como de mulheres, assim como na mídia. Tartaglione explica que há três tipos de expressões vulgares: blasfêmia, palavrão e imprecação.

Pensando na cultura como uma ação no mundo a qual tem uma razão de ser, percebese a necessidade da compreensão de aspectos linguísticos, relacionando-os a questões culturais e identitárias para que se desenvolva a consciência sociolinguística e comunicativa, a qual compreende e reflete sobre os tabus e os estereótipos disseminados na sociedade.

Nesse aspecto, podemos observar que existe um forte estereótipo difundido sobre o comportamento do italiano e do italodescendente em relação aos xingamentos. Ao longo das entrevistas coletadas, todos os entrevistados afirmaram que o italiano xinga demasiadamente: "Putana (risos). Porca vaca di una putana!!! (risos) E vai embora de tão bravos... Eles batem um dedo e xingam em italiano! (risos)" (MGIIIc).

Muitos entrevistados acham tal aspecto engraçado e se divertiram relembrando os termos de baixo calão: “[...] eu conheço todos. Porca Miseria, portati tua... Tudo! [Porco Dio?] Porco Dio! Essas coisas assim, é besteira a gente conhece... é mais falada, né” (HGIa); "Eu gosto dos xingamentos, adoro xingar (risos)" (HGIa); “[...] Era gostoso... às vezes a gente tava brincando daí fazia alguma coisa errada e ela [avó] xingava a gente em italiano e depois que eu fui saber que ela tava xingando em italiano. Era divertido viu. Era bom aquela época. (risos)" (MGIa). 
Nota-se, com os depoimentos acima, que muitos italodescendentes compreendem como os xingamentos fazem parte da italianidade e de certa forma até mesmo positiva. Nesse mesmo sentido, o entrevistado a seguir defende:

Porco Dio, mas podia ser também de surpresa... tudo dependia do momento... Era usada de forma meio generalizada... A blasfêmia, eles não pensavam em blasfêmia... "Porco dio, aquele cara....". Sem o sentido de ofesa à... Ah! Às vezes quando batia o martelo no dedo, ou o negócio ia mal, então sai debaixo... (risos) (HGIIIc).

Diversos outros entrevistados apontaram esse comportamento como algo negativo: "[Porco Dio?] Ixi... daí é triste, hein? Meu vô não parava de falar isso! [Sério?] Porco dio, Porca madona, Sacramento, Ti spaco la recia! (risos)" (HGIIb); "[Porco cane?] Sim. Qualche un dise Porca Madona, ma no me piase... I veci se ascoltava quando giocava bote..." (HGIIc); "Não gosto que tem italiano que falam muito palavrões, né. Meu sogro tinha uma boca pra xingar!!! (risos)" (MGIIIa); "É engraçado, porque os italianos usam [o termo figlio/fiôlo] mais pra falar palavrão, oh fiolo di un cane (risos). Ah. Isso seria uma parte da cultura que eu não gosto muito" (MGIIIb).

A entrevistada da faixa etária mais jovem, MGIa, porém, evidencia como a mudança nessa fronteira étnica começou a acontecer ainda com o pai dela em relação à avó: “Algumas vezes eu falei Porca Madona, porque eu lembrava da vó Rosa falando, e o pai não gostava de ouvir, eu lembro quando a vó falava ele brigava com ela também (risos). [...] A vó falava quando tava muito brava" (MGIa). Nesse mesmo sentido, outra entrevistada garante: “[Stronzo?] Sì. A gente esquece porque na minha família ninguém xinga...” (MGIIa). Tais depoimentos demostram o quanto a cultura não é estática nem uniforme, pois dizer que todos os italianos e/ou italodescendentes xingam seria muito generalizante.

Percebe-se, assim, que ao trabalhar com esses termos vulgares é importante evidenciar alguns aspectos da italianidade, da identidade étnica de muitos italodescendentes assim como dos italianos contemporâneos. Fica evidente, porém, que é importante observar que algumas marcas de identificação étnica mudam com o tempo, de geração para geração, dependendo do novo contexto, no caso, brasileiro. Nesse sentido, nota-se que o contato dos italodescendentes com outras culturas, (des/re)constroem a cultura desse grupo. Dessa forma, ao refletir sobre essas mudanças comportamentais, desconstroem-se estereótipos e (re)constroem-se consciências sociolinguísticas e socioculturais. Para isso, é necessário, porém, que o professor de LE vá além do manual didático, o qual traz apenas alguns apontamentos em relação a essa questão cultural e comportamental. Percebe-se, assim, a necessidade de ampliar tal aspecto 
nas aulas de LI, trazendo exemplos da mídia italiana assim como da comunidade italodescendente, podendo ser, até mesmo, a partir do conhecimento prévio do aluno de LI.

O ensino transversal de línguas, pela vertente INdisciplinar (MOITA LOPES, 2006) e transgressiva (PENNYCOOK, 2006) da Linguística Aplicada considera que os estudos de diversas áreas podem possibilitar uma melhor aprendizagem de uma língua, pois pelo viés da interdisciplinaridade, a LA mestiça ou nômade, faz com que se repense o ensino de língua a partir do contexto aplicado, “onde as pessoas vivem e agem" (MOITA LOPEZ, 2006, p. 21), proporcionando um letramento crítico.

Para Pichiassi (1999), a glotodidática associa a língua e a cultura, sendo esta, indispensável para que se aprenda um idioma de fato, até porque "la lingua è veicolo e allo stesso tempo manifestazione di cultura, per cui l'acquisizione di una lingua comporta l'assimilazione anche dei tratti culturali propri della società che usa quella lingua" (PICHIASSI, 1999, p. 23) ${ }^{4}$.

Dessa forma, para aprender uma língua é necessário aprender também as formas de expressões dessa língua, que se manifestam por meio da cultura. Sobre isso, Gimenez e Furtoso (2002, p. 51) também comentam, ao dizerem que o professor de língua estrangeira precisa conhecer outras culturas, pois "não é possível ensinar uma língua estrangeira desvinculada dos aspectos socioculturais e históricos que as constroem”.

\section{Conclusões}

Partindo de uma postura calcada na LA contemporânea e na abordagem intercultural, sem deixar de lado as abordagens comunicativa e sociointeracional, ou seja, a partir do pósmétodo, o professor precisa oportunizar trocas de conhecimentos culturais e linguísticos em sala de aula para que o aluno desenvolva uma leitura crítica sobre o país em que está vivendo, assim como sobre sua própria cultura, sobre seu próprio comportamento, crenças e valores. Mello, Santos e Almeida (2002, p. 96) falam sobre a importância de o professor desenvolver "não só a competência linguística de seus alunos, mas também a competência sociolingüística". Nesse sentido, trabalhar com termos vulgares, ou seja, com palavrões, xingamentos e blasfêmias é de extrema importância para o desenvolvimento da consciência e reflexão sobre a transformação da italianidade.

\footnotetext{
${ }^{4}$ a língua é veículo e ao mesmo tempo manifestação de cultura, por isso a aquisição de uma língua comporta a assimilação inclusive de comportamentos/aspectos culturais próprios da sociedade que utiliza aquela língua (PICHIASSI, 1999, p. 23, tradução nossa).
} 
A perspectiva intercultural pode ser, portanto, uma forma de contribuir, pois, assim como Mezzadri observa, "la competenza comunicativa interculturale non può essere insegnata; il docente di lingua straniera può solo insegnare a osservarla" (MEZZADRI, 2003, p. 239) ${ }^{5}$. Nesse sentido, o ensino de língua estrangeira pode ir além do objetivo de formar um falante competente. Pode ser uma maneira de contribuir com a formação crítica, com a formação humana de outros cidadãos, com a compreensão da própria italianidade e/ou da cultura do outro.

Compreender os fatores históricos, geográficos e sociais, os quais, consequentemente, delineiam as diversidades linguísticas e culturais de uma comunidade, no caso, a de italodescendentes em Cascavel, é de suma importância para que o ensino de língua italiana seja coerente. É função do professor de italiano, portanto, conhecer e entender como se configura o comportamento e a cultura italiana entre os ítalo-brasileiros e italianos contemporâneos.

\section{Referências}

BARICHELLO, Cesar Augusto; SANTOS, Julio Ricardo Quevedo dos. Grupos étnicos italianos, religiosidade e negociação de identidades na região central do Rio Grande do Sul. Revista Sociais e Humanas, Santa Maria, v. 25, n. 2, p.189-198, jul.dez. 2012.

BARTH, Frederik. Grupos étnicos e suas fronteiras. In: POUTIGNAT, Philippe; STREIFFFENART, Jocelyne. Teorias da etnicidade: seguido de grupos étnicos e suas fronteiras de Fredrik Barth. Tradução: Elcio Fernandes. 2. ed. São Paulo: Unesp, 2011.

BELONI, Wânia Cristiane. Um estudo sobre a fala e a cultura de italodescendentes em Cascavel/PR. 2015. p. 155. Dissertação (Mestrado em Letras) - Programa de Pós-Graduação em Letras, Universidade Estadual do Oeste do Paraná (Unioeste). Cascavel, 2015.

BOTTOMORE, Tom. Grupo. In: OUTHWAITE, William; BOTTOMORE, Tom. Dicionário do Pensamento Social do Século XX. Rio de Janeiro: Zahar, 1996.

BRITO, Danilo Lopes; BONA, Fabiano Dalla. Sobre a noção de estereótipo e as imagens do Brasil no exterior. Revista Graphos, João Pessoal, vol. 16, n. 2, 2014, p. 15-28.

DE GIULI, Alessandro; GUASTALLA, Carlo; NADDEO, Ciro Massimo. Magari: corso di lingua e cultura italiana di livello intermedio e avanzato. Firenze: Alma, 2008.

GIL, Antonio Carlos. Como elaborar projetos de pesquisa. 4. ed. São Paulo: Atlas, 2002.

\footnotetext{
5 “a competência comunicativa intercultural não pode ser ensinada; o docente de língua estrangeira pode apenas ensinar os estudantes a observá-la” (MEZZADRI, 2003, p. 239).
} 
GIMENEZ, Telma Nunes; FURTOSO, Viviane Bagio. Formação de professores de português para falantes de outras línguas: alguns apontamentos iniciais. In: CUNHA, Maria Jandyra Cavalcanti; SANTOS, Percília (Orgs.). Tópicos em Português Língua Estrangeira. Brasília: Universidade de Brasília, 2002.

GOFFMAN, Erving. A situação negligenciada. In: RIBEIRO, Branca Telles; GARCEZ, Pedro M. (Orgs.). Sociolingüística interacional: antropologia, lingüística e sociologia em análise do discurso. Porto Alegre: AGE, 1998. p. 11-15.

GUASTALLA, Carlo; NADDEO, Ciro Massimo. Domani 1: corso di lingua e cultura italiana. Firenze: Alma, 2010a.

$2010 b$.

Domani 1: guida per l'insegnante. Corso di lingua e cultura italiana. Firenze: Alma,

. Domani 2: corso di lingua e cultura italiana. Firenze: Alma, 2011a.

$2011 b$

Domani 2: guida per l'insegnante. Corso di lingua e cultura italiana. Firenze: Alma,

Domani 3: corso di lingua e cultura italiana. Firenze: Alma, 2012a.

. Domani 3: guida per l'insegnante. Corso di lingua e cultura italiana. Firenze: Alma,

$2012 b$.

Magari: guida per l'insegnante. Firenze: Alma, 2009.

GUMPERZ, John J. Convenções de contextualização. In: RIBEIRO, Branca Telles; GARCEZ, Pedro M. (Orgs.). Sociolingüística interacional: antropologia, lingüística e sociologia em análise do discurso. Porto Alegre: AGE, 1998.

HORA, Demerval da. Teoria da variação: trajetória de uma proposta. In: (Org.). Estudos sociolinguísticos. João Pessoa: UFPB, 2004.

MACHIOSKI, Fábio Luiz. Preservação da identidade cultural em um grupo imigrante italiano de Curato de Colombo, Paraná, 1888 - 1910. Monografia apresentada à disciplina de Estágio Supervisionado em Pesquisa Histórica como requisito parcial à conclusão do Curso de História, Setor de Ciências Humanas, Letras e Artes, Universidade Federal do Paraná. Curitiba, 2004.

MEIRA, Margarida. Acção do contexto nos estereótipos: influência e limites. 2010/2011. p. 56. Dissertação (Mestrado Integrado em Psicologia) - Secção de CogniçÃo Social Aplicada, Universidade de Lisboa/ Faculdade de Psicologia, Lisboa, 2010/2011.

MELLO, Ana Catarina Moraes Ramos Nobre de; SANTOS, Danúsia Torres dos; ALMEIDA, Patricia Maria Campos de. Leitura em PLE: reflexões. In: CUNHA, Maria Jandyra Cavalcanti; SANTOS, Percília (Orgs.). Tópicos em Português Língua Estrangeira. Brasília: Universidade de Brasília, 2002.

MEZZADRI, Marco. I Ferri del mestiere. Perugia: Guerra, 2003. 
MOITA LOPES, Luiz Paulo da. Uma linguística aplicada mestiça e ideológica: interrogando o campo como linguísta aplicado. In: MOITA LOPES, Luiz Paulo da (Org.). Por uma linguística aplicada INdisciplinar. São Paulo: Parábola, 2006, p. 13-42.

PENNYCOOK, Alastair. Uma linguística aplicada transgressiva. In: MOITA LOPES, Luiz Paulo da (Org.). Por uma linguística aplicada INdisciplinar. São Paulo: Parábola, 2006. p. 67-84.

PERTILE, Marley Terezinha. O Talian entre o italiano-padrão e o português brasileiro: manutenção e substituição linguística no Alto Uruguai gaúcho. Tese apresentada ao Programa de Pós-graduação em Letras da Universidade Federal do Rio Grande do Sul. Porto Alegre, 2009.

PESSANHA, Eurize Caldas; DANIEL, Maria Emília Borges; MENEGAZZO, Maria Adélia. Da história das disciplinas escolares à história da cultura escolar: uma trajetória de pesquisa. Revista Brasileira de Educação, Rio de Janeiro, n. 27, p. 57-69, set./dez. 2004.

PICHIASSI, Mauro. Fondamenti di glotodidattica. Perugia: Guerra Edizioni Guru, 1999.

POUTIGNAT, Philippe; STREIFF-FENART, Jocelyne. Teorias da etnicidade: seguido de grupos étnicos e suas fronteiras de Fredrik Barth. Tradução: Elcio Fernandes. 2. ed. São Paulo: Unesp, 2011.

RAJAGOPALAN, Kanavillil. O conceito de identidade em linguística: é chegada a hora para uma reconsideração radical? Tradução: Almiro Pisetta. In: SIGNORINI, Inês (Org.). Língua(gem) e identidade: elementos para uma discussão no campo aplicado. Campinas/São Paulo: Mercado de Letras/Fapesp, 1998.

RIBEIRO, Branca Telles; GARCEZ, Pedro M. (Orgs.). Sociolingüística interacional: antropologia, lingüística e sociologia em análise do discurso. Porto Alegre: AGE, 1998. p. 11-15.

ROJO, Roxane. Materiais didáticos no ensino de línguas. In: MOITA LOPES, Luiz Paulo da. Linguística aplicada na modernidade recente. São Paulo: Parábola, 2013.

THUN, Harald. A dialetologia pluridimensional no Rio da Prata. In: ZILLES, Ana Maria Stahl. Estudos de Variação Lingüística no Brasil e no Cone Sul. Porto Alegre: Editora da UFRGS, 2005. 